\title{
Revisão dos gêneros Tropanisopodus Tippmann e Paranisopodus Monné \& Martins (Coleoptera, Cerambycidae, Lamiinae)
}

\author{
Marcela L. Monné ${ }^{1} \&$ Miguel A. Monné ${ }^{1,2}$ \\ ${ }^{1}$ Museu Nacional, Universidade Federal do Rio de Janeiro. Quinta da Boa Vista, São Cristovão, 20940-040 Rio de Janeiro, \\ Rio de Janeiro, Brasil. \\ 2 Bolsista do CNPq.
}

\begin{abstract}
Revision of the genera Tropanisopodus Tippmann and Paranisopodus Monné \& Martins (Coleoptera, Cerambycidae, Lamiinae). The genera Tropanisopodus Tippmann, 1960 and Paranisopodus Monné \& Martins, 1976 are revised. Tropanisopodus tachira sp. nov. is described from Venezuela. Seven species are recognized in Paranisopodus, of which five are new: P. hovorei sp. nov. from Costa Rica, P. granulosus sp. nov. from Panama, $P$. araguaensis sp. nov. from Venezuela, $P$. peruanus sp. nov. from Peru and P. genieri sp. nov. from Bolivia. A key to species is provided. Paranisopodus paradoxus Monné \& Martins, 1976 is recorded from Equador. KEY WORDS. Acanthocinini; new species; key; Neotropical.
\end{abstract}

RESUMO. Os gêneros Tropanisopodus Tippmann, 1960 e Paranisopodus Monné \& Martins, 1976 são revistos. Tropanisopodus tachira sp. nov. é descrita da Venezuela. São reconhecidas sete espécies em Paranisopodus, das quais cinco novas: $P$. hovorei sp. nov. da Costa Rica, P. granulosus sp. nov. do Panamá, P. araguaensis sp. nov. da Venezuela, P. peruanus sp. nov. do Peru e P. genieri sp. nov. da Bolívia. Chave para identificação das espécies é fornecida. Paranisopodus paradoxus Monné \& Martins, 1976 é registrada para o Equador.

PALAVRAS-CHAVE. Acanthocinini; novas espécies; chave; Neotropical.

Os gêneros Tropanisopodus Tippmann, 1960 e Paranisopodus Monné \& Martins, 1976 pertencem à tribo Acanthocinini, atualmente com 149 gêneros na Região Neotropical (Monné 2005). Tropanisopodus foi proposto por TIPPMANN (1960) para T. andinus da Bolívia e, neste trabalho, o gênero é redescrito e uma nova espécie é descrita da Venezuela.

Monné \& Martins (1976) descreveram Paranisopodus para $P$. heterotarsus da Costa Rica e P. paradoxus da Colômbia. O gênero é redescrito, cinco novas espécies descritas, amplia-se a distribuição de $P$. paradoxus para o Equador e chave para as espécies é fornecida.

As siglas mencionadas no texto referem-se às seguintes instituições: (CMNC) Canadian Museum of Nature, Ottawa, Canadá; (FAUV) Facultad de Agronomia, Universidad Central de Venezuela, Maracay, Aragua, Venezuela; (MNRJ) Museu Nacional, Universidade Federal do Rio de Janeiro, Rio de Janeiro, Brasil. As dimensões são fornecidas em milímetros.

\section{Tropanisopodus Tippmann, 1960}

Tropanisopodus Tippmann, 1960: 184; Monné, 2005: 142 (cat.).

Espécie-tipo: Tropanisopodus andinus Tippmann, 1960 por designação original e monotipia.

Corpo com aspecto achatado. Lobos superiores dos olhos tão distantes entre si quanto o dobro do diâmetro de um lobo; lobos inferiores sub-retangulares, mais de duas vezes a largura das genas. Sulco interocular profundo. Antenas com onze antenômeros; antenômero III o mais longo, IV-XI gradualmente mais curtos.

Protórax mais largo do que longo, com tubérculo aguçado e perpendicular, apenas pós-mediano; bordo anterior do tubérculo lateral com lobo arredondado pouco projetado. Pronoto com dois tubérculos subarredondados antes do meio e um longitudinal, mais raso, centro-posterior. Élitros achatados, pelo menos cinco vezes mais longos que o protórax; superfície sem cerdas, sem crista centro-basal e com carenas laterais; lados paralelos até o início do quarto apical, depois estreitados até a extremidade distal. Úmeros proeminentes, projetados para frente. Processo prosternal com metade a 3/4 da largura de uma procoxa; processo mesosternal sem tubérculos, com metade a 3/4 da largura de uma mesocoxa.

Pernas posteriores cerca de duas vezes mais longas que as anteriores. Meso- e metafêmures pedunculado-clavados ou alargados gradualmente no terço distal. Nos machos, o ápice dos metafêmures apenas ultrapassa a extremidade dos élitros e, nas fêmeas, não alcança os ápices.

Discussão. Tropanisopodus assemelha-se a Anisopodus White, 1855 e Paranisopodus pelo aspecto achatado do corpo, protórax com tubérculos laterais, élitros sem cerdas subdecum- 
bentes e pelas pernas posteriores dos machos distintamente desenvolvidas, com os metafêmures ultrapassando os ápices elitrais. Difere de Anisopodus pelos tubérculos laterais do protórax apenas pós-medianos, aguçados e direcionados para os lados; em Anisopodus os tubérculos são diminutos e situam-se nitidamente no terço posterior. Distingue-se de Paranisopodus pelos élitros com carena lateral e ausência de crista centro-basal; em Paranisopodus os élitros não têm carena lateral e apresentam crista centro-basal. Difere ainda de Anisopodesthes Melzer, 1931 pelo protórax com tubérculos laterais, ausentes em Anisopodesthes.

\section{Tropanisopodus andinus Tippmann, 1960}

Fig. 1

Tropanisopodus andinus Tippmann, 1960: 185, pr. 9, fig. 25b; Monné, 2005: 142 (cat.).

Tippmann (1960) descreveu minuciosamente o macho desta espécie e, em relação à fêmea, apenas indicou que o ovipositor não alcança os ápices dos élitros. A descrição da fêmea é complementada a seguir.

Fêmea. Antenas atingem os ápices dos élitros no terço anterior do antenômero VIII. Urotergito V arredondado na margem apical; urosternito $V$ com a margem apical semicircularmente chanfrada e ângulos projetados em curto espinho obtuso.

Localidade-tipo: Bolívia, Yungas de Corani (USNM). Distribuição: Bolívia.

Material examinado. Bolívia, La Paz: Rio Zongo, 2200 m, fêmea, X.1984, L.E. Peña G. leg. (MNRJ).

\section{Tropanisopodus tachira sp. nov.}

Fig. 2

Fêmea. Tegumento predominantemente castanho-avermelhado. Tegumento castanho-escuro: quarto distal dos antenômeros III-VI, metade apical dos antenômeros VII-IX e a totalidade dos antenômeros X-XI; no pronoto, uma mancha a cada lado do meio; nos élitros, máculas pequenas ao longo da metade basal da carena lateral e na metade distal, junto à sutura; e metade apical das protíbias e tarsos. Pubescência de maneira geral acinzentada; a pubescência preta reveste os tubérculos laterais do pronoto. Metade látero-posterior dos élitros com pequenos tufos de pêlos branco-acinzentados, dispostos em fileiras longitudinais.

Antenas alcançam os ápices dos élitros na extremidade distal do antenômero VII. Pronoto com pontuação profunda e moderadamente densa junto aos bordos anterior e posterior. Processos prosternal e mesosternal com 3/4 da largura de uma procoxa e mesocoxa, respectivamente. Élitros com pontuação fina e moderadamente densa em toda a superfície; carena lateral nitidamente demarcada e duas carenas rasas dorsais, que não alcançam os ápices; extremidades chanfradas, com ambos os ângulos projetados em espinho curto.

Pro- e mesofêmures clavados; metafêmures longos, apenas engrossados no terço distal. Metatarsômero I longo, duas vezes mais longo que II+III.
Urotergito V arredondado na margem apical; urosternito V semicircularmente emarginado.

Dimensões, holótipo fêmea. Comprimento total, 15,0; comprimento do protórax, 2,0; maior largura do protórax., 4,0; comprimento do élitro, 12,0; largura umeral, 5,2.

Material-tipo. Holótipo fêmea, Venezuela, Tachira: Páramo Zumbador, 2600 m, 25.IX.1966, C.J. Rosales \& J. Salcedo leg. (FAUV).

Discussão. Tropanisopodus tachira sp. nov. (Fig. 2) separase de T. andinus Tippmann, 1960 (Fig. 1) pela ornamentação elitral que consiste de fileiras longitudinais de pêlos brancoacinzentados junto à margem lateral na metade distal, pelos élitros com duas carenas dorsais rasas nos três quartos anteriores e pelos metafêmures levemente engrossados para os ápices. Em T. andinus, os élitros apresentam uma mancha preta lateral levemente escavada, no início da metade distal, circundada de pilosidade castanho-amarelada; os élitros não possuem vestígios de carenas dorsais e os metafêmures são nitidamente engrossados na metade distal.

Etimologia. Referente ao Estado da Venezuela onde foi coletado o holótipo.

\section{Paranisopodus Monné \& Martins, 1976}

Paranisopodus Monné \& Martins, 1976: 59; Monné, 2005: 117 (cat.).

Espécie-tipo: Paranisopodus heterotarsus Monné \& Martins, 1976 por designação original.

Corpo com aspecto achatado. Lobos superiores dos olhos mais distantes entre si que o dobro do diâmetro de um lobo; lobos inferiores sub-retangulares, mais de duas vezes a altura das genas. Sulco interocular profundo. Antenas com onze antenômeros; antenômero III o mais longo, cerca de $1 / 3$ mais longo que o escapo; IV-XI gradualmente encurtados para o ápice.

Protórax mais largo do que longo, com tubérculo lateral perpendicular ao eixo do corpo, apenas pós-mediano e aguçado no ápice. Pronoto com dois tubérculos subarredondados antes do meio e um longitudinal, mais raso, centro-posterior. Élitros achatados, pelo menos quatro vezes mais longos que o protórax; superfície sem cerdas, com crista centro-basal e sem carenas laterais. Úmeros proeminentes, projetados para frente (exceto em $P$. peruanus sp. nov.).

Pernas posteriores cerca de duas vezes mais longas que as anteriores. Mesofêmures distintamente pedunculado-clavados; metafêmures alargados gradualmente no terço distal. Nos machos, o ápice dos metafêmures ultrapassa a extremidade distal dos élitros e, nas fêmeas, não alcançam os ápices.

Discussão. Ver discussão em Tropanisopodus.

\section{Chave para as espécies de Paranisopodus}

1. Pronoto com tubérculos anteriores distintamente desenvolvidos, arredondados superiormente e separados por depressão profunda ....................................................................... 2

1'. Pronoto com tubérculos anteriores rasos, sem depressão profunda entre eles .......................................................... 5 
2. Crista centro-basal dos élitros com grânulos abundantes; terço basal ventral dos mesofêmures com marcada escavação semicircular; metatarsômero I dilatado no ápice e com cerdas densas e eretas..... 3

2'. Crista centro-basal dos élitros com escassos grânulos; terço basal dos mesofêmures sem escavação; metatarsômero I não dilatado no ápice, sem cerdas densas

3. Élitros com crista centro-basal longitudinal e tubérculo mediano elevado; metasterno, nos machos, com fileira látero-posterior, elevada e oblíqua de tubérculos brilhantes (Fig. 3). Costa Rica P. heterotarsus Monné \& Martins

3 '. Élitros com crista centro-basal arredondada e tubérculo mediano raso; metasterno, nos machos, sem fileira de tubérculos látero-posterior (Fig. 4). Bolívia P. genieri sp. nov.

4. Superfície do pronoto, entre os tubérculos anteriores, sem pontos; tubérculos laterais do protórax com projeção arredondada na margem anterior; élitros com grânulos ornados com uma curta cerda dirigida para trás; crista centro-basal dos élitros com escassos grânulos glabros, sem pontos; metatarsômero I tão longo quanto II+III (Fig. 5). Panamá P. granulosus sp. nov.

4'. Superfície do pronoto, entre os tubérculos anteriores, com pontos densos e profundos; tubérculos laterais do protórax sem projeções na margem anterior; élitros com grânulos sem cerda dirigida para trás; crista centro-basal com grânulos abundantes na margem anterior e pontos profundos no topo; metatarsômero I mais longo que II+III (Fig. 6). Costa Rica $P$. hovorei sp. nov.

5. Élitros com crista centro-basal alongada, sem tubérculos no topo; metatarsômero I dilatado no ápice, com espinho aguçado dirigido para cima (Fig. 7). Colômbia, Equador . P. paradoxus Monné \& Martins

5'. Élitros com crista centro-basal subarredondada, com tubérculos no topo, ainda que escassos; metatarsômero I com ápice inerme

6. Quarto basal dos élitros com grânulos pequenos e abundantes; pubescência elitral predominantemente esverdeada (Fig. 8). Peru .P. peruanus sp. nov.

6'. Quarto basal dos élitros sem grânulos; pubescência elitral predominantemente castanho-clara e castanho-amarelada (Fig. 9). Venezuela P. araguaensis sp. nov.

\section{Paranisopodus heterotarsus Monné \& Martins, 1976}

\section{Fig. 3}

Paranisopodus heterotarsus Monné \& Martins, 1976: 61, figs 1-5, 22; Chemsak et al., 1992: 144 (cat.); Monné, 2005: 118 (cat.).

Monné \& MarTins (1976) descreveram e ilustraram minuciosamente $P$. heterotarsus, com base em um exemplar macho da Costa Rica, inclusive a escavação ventral dos mesofêmures e o espinho do metatarsômero I. Paranisopodus heterotarsus (Fig. 3) assemelha-se a P. genieri sp. nov. (Fig. 4) e difere pelos caracteres da chave. Ver também discussão em $P$. hovorei sp. nov.
Distribuição. Conhecida apenas da Costa Rica.

Material examinado. Costa Rica, Puntarenas: San Vito, Las Cruces, macho, 6.III.1972, R.L. Brown leg. (MNRJ).

\section{Paranisopodus genieri sp. nov.}

\section{Fig. 4}

Macho. Tegumento predominantemente preto. Tegumento castanho-avermelhado: antenômeros III-XI (exceto ápice); faixa longitudinal nos élitros junto à sutura; metade basal dos meso- e metafêmures e das meso- e metatíbias; metarsômero I (exceto ápice). Metade póstero-lateral dos élitros verde-oliváceo, com máculas de castanho-escuro. Pubescência de maneira geral acastanhada, rala, não oculta o tegumento. Pubescência acinzentada: escapo e metade distal dos fêmures, com pequenas máculas glabras; protórax, mais esparsa no centro do pronoto; base dos élitros e faixa oblíqua mediana na margem anterior dos tubérculos elitrais.

Antenas alcançam as extremidades dos élitros no ápice do antenômero VI. Pronoto com tubérculos anteriores distintamente desenvolvidos, arredondados superiormente e separados por depressão profunda; pontuação moderadamente uniforme, exceto na superfície dos tubérculos. Processos prosternal e mesosternal com 3/4 da largura de uma pro- e mesocoxa, respectivamente. Metasterno sem tubérculos.

Élitros com crista centro-basal de contorno circular, com grânulos glabros, brilhantes no topo e abundantes; ápices obliquamente chanfrados, ângulos obtusos. No meio dos élitros com dois tubérculos pequenos, o interno mais desenvolvido que o externo; terço basal com pequenos grânulos glabros e brilhantes; pontuação moderadamente grossa e densa em toda a superfície.

Protíbias recurvas e alargadas para a extremidade distal; mesotíbias com projeção dentiforme na margem anterior de profunda escavação látero-posterior, tornando as mesotíbias fortemente pedúnculo-clavadas. Metafêmures ultrapassam os ápices dos élitros; metarsômero I mais de duas vezes o comprimento de II+III. Urotergito e urosternito V transversalmente truncados na margem apical.

Dimensões, holótipo macho. Comprimento total, 9,0; comprimento do protórax 1,7; maior largura do protórax, 3,0; comprimento do élitro, 6,3; largura umeral, 5,0.

Material-tipo. Holótipo macho, Bolívia, Santa Cruz: 32,8 km NW Comarapa, Kara Huasi, Yungas de la Sibéria, 1949’20"S, 64²'31"W, 2400 m, 27.I.1999, F. Genier leg. (MNRJ).

Discussão. Paranisopodus genieri sp. nov. (Fig. 4) pertence ao grupo de espécies com tubérculos proeminentes no pronoto, principalmente os dois anteriores. Separa-se de $P$. paradoxus Monné \& Martins, 1976 (Fig. 7), entre outros caracteres, pela projeção dentiforme nas mesotíbias e pela ausência de fileira oblíqua de tubérculos na margem posterior do metasterno.

Etimologia. O nome homenageia F. Genier (CMNC), coletor do holótipo, gentilmente cedido ao MNRJ. 


\section{Paranisopodus granulosus sp. nov.}

\section{Fig. 5}

Fêmea. Corpo fortemente achatado. Tegumento predominantemente castanho-escuro; castanho-avermelhado na metade distal dos élitros, face ventral, base dos fêmures e tíbias. Pubescência de maneira geral castanho-acinzentada; pubescência castanho-escura recobre base e ápice dos antenômeros III-XI e faixa longitudinal mediana no escutelo. Pubescência preta, aveludada, numa mancha ocelar pós-mediana nos élitros, de superfície ligeiramente elevada e parcialmente circundada por pubescência amarelada.

Antenas alcançam os ápices dos élitros na extremidade distal do antenômero XI. Tubérculos laterais do protórax com projeção arredondada na margem anterior. Pronoto com tubérculos anteriores distintamente desenvolvidos, arredondados superiormente e separados por depressão profunda. Pontos muito escassos, restritos ao centro das margens anterior e posterior. Processos prosternal e mesosternal da mesma largura que uma proou mesocoxa, respectivamente. Metasterno sem tubérculos.

Crista centro-basal dos élitros rasa e com escassos grânulos glabros; superfície recoberta por abundantes grânulos glabros, pretos e brilhantes, cada um com uma curta cerda rígida subdecumbente, dirigida para trás; metade posterior das margens elitrais com diminutos tufos de pêlos cinzento-acastanhados; ápices obliquamente chanfrados, ângulo externo projetado em curto espinho aguçado.

Protíbias ligeiramente curvas, alargadas para o extremo distal. Metatarsômero I tão longo quanto II+III.

Urotergito V arredondado na margem apical; urosternito $\mathrm{V}$ semicircularmente chanfrado.

Dimensões, holótipo fêmea. Comprimento total, 14,0, comprimento do protórax, 2,5; maior largura do protórax, 5,0; comprimento do élitro, 11,0, largura umeral, 6,0.

Material-tipo. Holótipo fêmea. PAnAmÁ, Chiriquí: El Hato del Volcán, Quebrada Tisingal, 1400 m, 3.V.1980, PorionBertrand leg. (MNRJ).

Discussão. Os abundantes grânulos pretos e brilhantes nos élitros, o corpo fortemente achatado e os tubérculos laterais do protórax com evidente expansão arredondada na margem anterior permitem o reconhecimento de $P$. granulosus sp. nov. (Fig. 5).

Etimologia. Do latim granum. O epíteto faz referência aos abundantes grânulos na superfície dos élitros.

\section{Paranisopodus hovorei sp. nov. \\ Fig. 6}

Fêmea. Tegumento de maneira geral preto, brilhante. Tegumento castanho-escuro: antenômeros II-XI, tíbias e tarsos. Tegumento preto mais visível nos tubérculos do pronoto, nos élitros, na crista centro-basal e nos grânulos, mais elevados nos 2/3 anteriores. Pubescência predominantemente acinzentada; pubescência castanho-escura recobre uma mancha a cada lado do meio do occipício, o terço distal dos antenômeros III-VII, a totalidade dos antenômeros VIII-X, centro do escutelo e o quarto distal do metatarsômero I. Pubescência amarelo-escura aos lados do escutelo e numa faixa estreita no quinto basal da sutura.

Antenas alcançam as extremidades dos élitros no ápice do antenômero X. Pronoto com tubérculos anteriores distintamente desenvolvido, arredondados superiormente e separados por depressão profunda; pontos profundos e densos entre os tubérculos e numa fileira junto aos bordos anterior e posterior. Processo prosternal com a metade da largura de uma procoxa; processo mesosternal com $2 / 3$ da largura de uma mesocoxa. Metasterno com fileira oblíqua, látero-posterior de pequenos grânulos brilhantes.

Élitros com crista centro-basal pouco elevada, arredondada, com pontos no topo e grânulos glabros na margem anterior; terço látero-posterior com área levemente deprimida; grânulos com um ponto profundo no topo, sem cerdas dirigidas para trás; ápices de per si acuminados, ângulos inermes.

Metatarsômero I cerca de 1,5 vezes o comprimento dos II-III. Urotergito e urosternito V transversalmente truncados.

Dimensões, fêmea. Comprimento total, 13,0; comprimento do protórax, 2,0; maior largura do protórax, 4,0; comprimento do élitro, 9,8; largura umeral, 5,8.

Material-tipo. Holótipo fêmea, Costa Rica, Puntarenas: La Palma, 5000 feet, 22.VII.1927, Tristán \& Rehn leg. (MNRJ).

Discussão. O aspecto da crista centro-basal dos élitros, arredondada, com pontos profundos no topo e grânulos glabros e brilhantes na margem anterior possibilitam separar $P$. hovorei sp. nov. (Fig. 6) de P. heterotarsus Monné \& Martins, 1976 (Fig. 3); nesta espécie a crista é alongada e com numerosos grânulos glabros no topo.

Etimologia. O epíteto é uma homenagem ao saudoso colega e amigo Frank T. Hovore (Santa Clarita, Califórnia).

\section{Paranisopodus paradoxus Monné \& Martins, 1976}

Fig. 7

Paranisopodus paradoxus Monné \& Martins, 1976: 61, figs 6, 23; Monné, 2005: 118 (cat.).

Monné \& Martins (1976) descreveram Paranisopodus paradoxus com base em um exemplar macho da Colômbia. Ampliamos sua distribuição para o Equador. Paranisopodus paradoxus (Fig. 7) assemelha-se a P. araguaensis sp. nov. (Fig. 9) e $P$. peruanus (Fig. 8) e difere pelas características da chave. Ver discussão em Paranisopodus genieri sp. nov.

Distribuição: Colômbia e Equador.

Material examinado. Equador, Napo: Cosanga, 3 machos, 26.X.1997, F. T. Hovore leg. (MNRJ).

\section{Paranisopodus peruanus sp. nov.}

\section{Fig. 8}

Fêmea. Tegumento preto. Pubescência predominantemente cinzento-esverdeada. Pubescência castanho-escura recobre a extremidade distal dos antenômeros III-VII; uma mancha longitudinal a cada lado do meio do pronoto; nos élitros, uma 

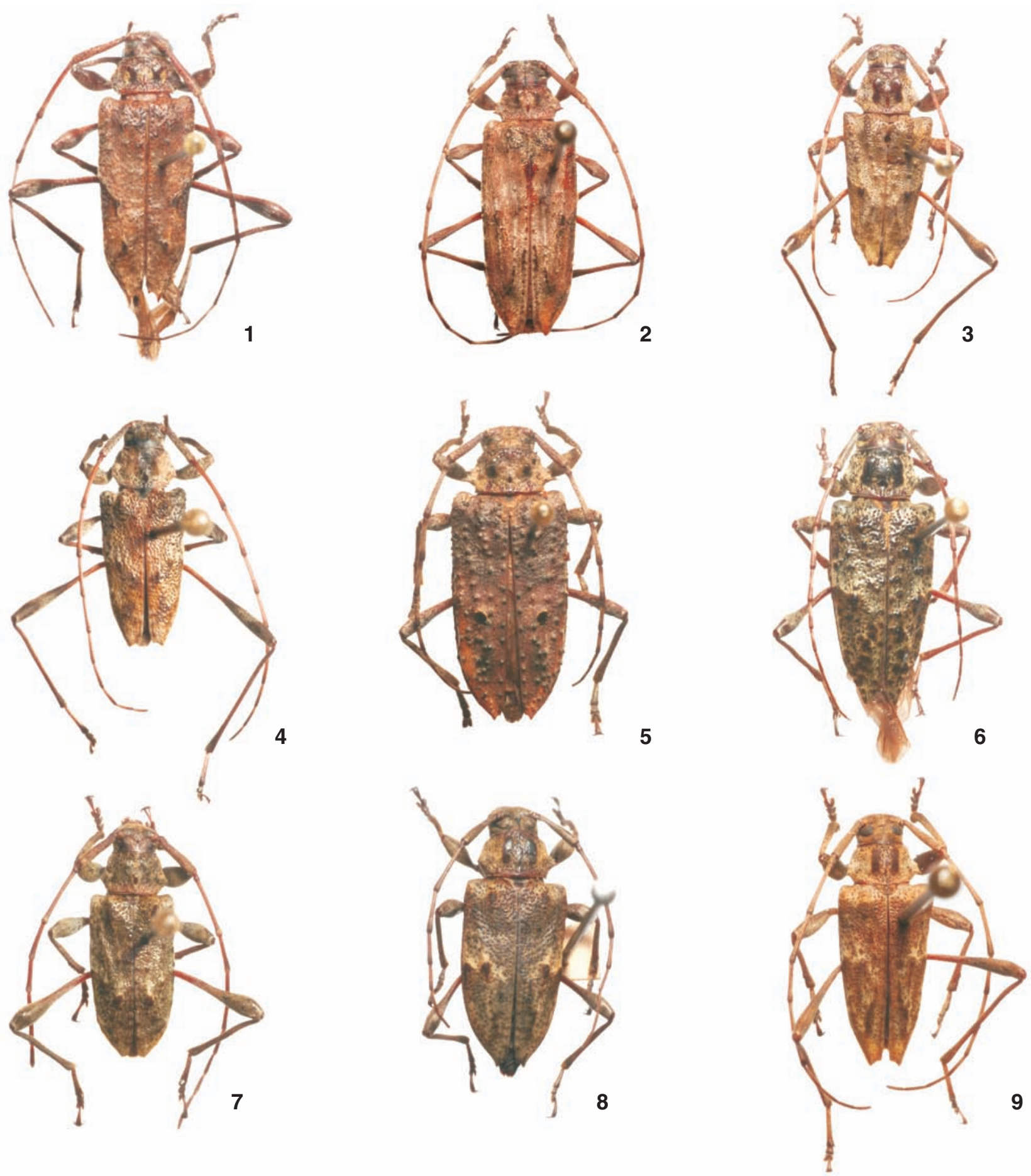

Figuras 1-9. (1) Tropanisopodus andinus, macho, comprimento 13,0 mm; (2) T. tachira sp. nov., holótipo fêmea, comprimento 15,0 mm; (3) Paranisopodus heterotarsus, macho, comprimento 13,5 mm; (4) P. genieri sp. nov., holótipo macho, comprimento 9,0 mm; (5) P. granulosus sp. nov., holótipo fêmea, comprimento 14,0 mm; (6) P. hovorei sp. nov., holótipo fêmea, comprimento 13,0 mm; (7) $P$. paradoxus, macho, comprimento $9,0 \mathrm{~mm}$; (8) P. peruanus sp. nov., holótipo fêmea, comprimento 11,0 mm; (9) P. araguaensis sp. nov., holótipo macho, comprimento $9,0 \mathrm{~mm}$. 
manha na crista centro-basal e duas máculas arredondadas medianas, mais próximas da margem que da sutura, localizadas numa elevação rasa. Pubescência castanho-amarelada reveste os lados do pronoto, a base dos élitros e faixa mediana transversal em ziguezague, na margem anterior das máculas castanho-escuras dos élitros.

Ápice do antenômero X alcança o quinto distal dos élitros (faltam os antenômeros XI). Pronoto com tubérculos anteriores rasos, sem depressão profunda e pontos profundos e moderadamente grossos entre os tubérculos laterais e junto às margens anterior e posterior. Processo prosternal com três quartos da largura de uma procoxa; processo mesosternal com a mesma largura que uma mesocoxa. Metasterno sem tubérculos.

Élitros com crista centro-basal subarredondada, rasa e com pequenos grânulos glabros, pretos e brilhantes, que recobrem o quarto basal elitral, entre as cristas, e pontos pequenos e esparsos no restante da superfície; ápices de per si acuminados, ângulo externo com pequeno espinho aguçado. Úmeros não projetados.

Protíbias ligeiramente curvas e gradativamente alargadas para a extremidade distal.

Urotergito V largamente arredondado; urosternito V semicircularmente chanfrado.

Dimensões, holótipo fêmea. Comprimento total, 11,0; comprimento do protórax, 2,0; maior largura do protórax, 3,0; comprimento do élitro, 7,8; largura umeral, 3,8.

Material-tipo. Holótipo fêmea, Peru, Cuzco: Ruta CuzcoManu, km 115, 3200 m, 8.XII.1979, T. Porion leg. (MNRJ).

Discussão. Vide discussão em $P$. araguaensis sp. nov.

Etimologia. O termo refere-se ao país onde foi coletado o holótipo.

\section{Paranisopodus araguaensis sp. nov.} Fig. 9

Macho. Tegumento de maneira geral castanho-avermelhado; extremidade distal dos antenômeros III-VIII e pernas, castanho-escuros. Pubescência predominantemente castanha; pubescência castanho-escura recobre uma mancha longitudinal, de lados paralelos, a cada lado do meio do pronoto e, nos élitros, estreita faixa transversal látero-mediana, situada numa elevação rasa e mácula oblíqua longitudinal no terço distal. Pubescência amarelo-acastanhada reveste os lados do pronoto; nos élitros, a região basal, uma mancha conspícua antes das manchas castanho-escuras e máculas difusas no terço distal.

Antenas atingem a extremidade dos élitros no ápice do antenômero VII. Pronoto com tubérculos anteriores rasos, sem depressão; pontuação restrita à região centro-mediana entre os tubérculos e às fileiras juntos às margens anterior e posterior. Processo prosternal com largura igual a 3/4 de uma procoxa; processo mesosternal da mesma largura que uma mesocoxa. Metasterno sem tubérculos.

Élitros com crista centro-basal rasa, arredondada, sem grânulos glabros e com pontos escassos; ápices oblíqua e semicircularmente chanfrados, ângulos não projetados em espinho agu- çado. Úmeros com uma elevação inconspícua póstero-lateral.

Protíbias levemente recurvas, gradualmente alargadas para a extremidade distal. Mesofêmures acentuadamente escavados no quarto basal, com a face ventral subglabra e brilhante. Metatarsômero I com mais de três vezes o comprimento dos II+III, com pequeno tufo de cerdas curtas e pretas na extremidade distal.

Urotergito $\mathrm{V}$ triangularmente entalhado na margem apical; urosternito $\mathrm{V}$ com a margem arredondada.

Fêmea. Antenas alcançam as extremidades dos élitros no ápice do antenômero VIII; urotergito e urosternito V truncados; metafêmures atingem a quinto distal dos élitros; metatarsômero I duas vezes o comprimento dos II+III.

Dimensões, macho/fêmea. Comprimento total, 9,0/9,0; comprimento do protórax, 1,6/1,3; maior largura do protórax, 2,5/2,3; comprimento do élitro, 6,4/6,6; largura umeral, 3,2/3,2.

Material-tipo. Holótipo macho, Venezuela, Aragua: Rancho Grande, 1100 m, 18.V.1975, J. Salcedo \& J.A. Clavijo leg. (FAUV). Parátipos: mesma procedência, macho, 25.IV.1949, F. Fernández leg. (FAUV); fêmea, 13.VII.1967, L. Rodriguez \& A. Ramirez leg. (MNRJ); macho, 14.VII.1967, J. Salcedo \& G. Andara leg. (MNRJ).

Discussão. Os úmeros levemente projetados para frente, a presença de elevação pós-umeral, o metatarsômero I muito alongado nos machos e com tufo de cerdas pequenas na extremidade distal permitem separar, além dos caracteres da chave, $P$. araguaensis sp. nov. (Fig. 9) de $P$. peruanus sp. nov. (Fig. 8).

Etimologia. O epíteto refere-se ao Estado da Venezuela onde foram coletados todos os exemplares.

\section{AGRADECIMENTOS}

A Luis J. Joly (FAUV) pelo empréstimo dos exemplares. A José Ricardo M. Mermudes (Universidade do Estado do Rio de Janeiro) pela execução das fotos.

\section{REFERÊNCIAS BIBLIOGRÁFICAS}

Chemsak, J.A.; E.G Linsley \& F.A. Noguera. 1992. Listados faunísticos de México. II. Los Cerambycidae y Disteniidae de Norteamérica, Centroamérica y las Indias Occidentales (Coleoptera). México, Universidad Nacional Autónoma, 204p.

Monné, M.A. 2005. Catalogue of the Cerambycidae (Coleoptera) of the Neotropical Region. Part II. Subfamily Lamiinae. Zootaxa 1023: 1-759.

Monné, M.A. \& U.R. Martins. 1976. Contribuição ao conhecimento dos Acanthocinini (Coleoptera, Cerambycidae, Lamiinae). Papéis Avulsos de Zoologia 30 (4): 43-98.

TIPpMann, F.F. 1960. Studien über neotropische Longicornier III (Coleoptera, Cerambycidae). Koleopterologische Rundschau 37-38: 82-217.

Recebido em 05.VI.2007; aceito em 21.XI.2007. 